\title{
Measurement of modulus of subgrade reaction for geogrid stabilized roadways
}

\author{
Prajwol Tamrakar, Mark H. Wayne \& Garrett Fountain \\ Tensar International Corporation, Alpharetta, GA, USA \\ David J. White \& Pavana Vennapusa \\ Ingios Geotechnics, Northfield, MN, USA
}

\begin{abstract}
Performance of rigid pavements depends primarily upon uniformity in the slab support condition and a composite response of unbound aggregate layers and subgrade. Several pavement design and analysis methods (e.g., AASHTO, PCA) consider modulus of subgrade reaction (k-value) as one of the key parameters representing pavement foundation strength. The k-value is represented by the reaction pressure required for per unit settlement and is directly influenced by the characteristics of unbound pavement layers and subgrade strength. AASHTO T222 provides guidance for measuring k-value in the field for ensuring that the compacted aggregate layers have achieved the target stiffness. However, such a method of measuring in-situ $\mathrm{k}$-value is not common in practice. As an alternative, some empirical approaches are available for estimating "theoretical" $\mathrm{k}$-value that include backcalculating FWD deflection data or correlating with material stiffness parameters. This paper presents k-value test results from static plate load testing on geogrid stabilized and unstabilized roadways at two sites. Two types of multi-axial geogrid were selected for constructing two separate stabilized aggregate layers over the existing subgrade. An Automated Plate Load Testing (APLT) system was used for conducting the static plate load tests to measure k-value, by following the AASHTO T222 protocol. At the first site, the aggregate base course (ABC) thicknesses of the stabilized and unstabilized sections were $125 \mathrm{~mm}$ and $287 \mathrm{~mm}$, respectively. Similarly, the ABC thicknesses of the stabilized and unstabilized sections were $118 \mathrm{~mm}$ and $212 \mathrm{~mm}$ at the second site. Despite this reduction in thickness, the geogrid stabilized sections exhibited higher k-values in comparison to the unstabilized sections.
\end{abstract}

Keywords: Geogrid, stabilization, k-value, rigid Pavement, AASHTO T222

\section{INTRODUCTION}

Rigid pavements (e.g., cement concrete slab) are different from flexible pavements (e.g., asphalt concrete layer) in terms of the durability of the material, method of construction and distribution of vehicle loads to the underlying pavement layers. In the rigid pavement, the vehicle loads are distributed in a wider area and at the shallow depth through the concrete slab. On the contrary, the loads are distributed narrowly and deeply under the asphalt concrete layer in flexible pavements. Further, the stiffness or rigidity of cement concrete is significantly higher than that of asphalt concrete. Therefore, the performance of rigid pavements depends primarily upon uniformity in the slab support condition and a composite response of unbound aggregate layers and subgrade (White et al. 2004). 
Rigid pavements are commonly represented by a slab-spring model where the interaction between the slab and foundation is characterized by the spring component (Westergaard 1926). Winkler (1867) proposed such a model consisting of a linear elastic spring. Several other researchers had contributed to improve the slab-spring model by considering the variants such as shear interactions of slab-foundation interface (Shi et al. 1994), realistic contact stresses and the nonlinear stress-dependent elastoplastic characteristics of unbound pavement materials (Farouk and Farouk 2014), cross anisotropic behavior of aggregate base course (Saha et al. 2019).

Although several sophisticated slab-spring models are available to date, most pavement design and analysis methods (e.g., AASHTO, PCA) depend on the modulus of subgrade reaction ( $\mathrm{k}$-value) based on the Winkler model. The $\mathrm{k}$-value is considered as one of the key parameters representing pavement foundation strength and is represented by the reaction pressure required for per unit settlement which is directly influenced by the characteristics of unbound pavement layers and subgrade strength. AASHTO T222 provides guidance for measuring $\mathrm{k}$-value in the field for ensuring that the compacted aggregate layers have achieved the target stiffness. However, such a method of measuring in-situ k-value is not common in practice. As an alternative, some empirical approaches are available for estimating "theoretical" k-value that include back-calculating FWD deflection data or correlating with material stiffness parameters (Darter et al. 1995).

This paper presents a direct measurement of the k-value for geogrid stabilized and unstabilized roadways. Two types of multi-axial geogrid were selected for constructing two separate stabilized aggregate layers over the existing subgrade. An Automated Plate Load Testing system was used for measuring k-value by following the AASHTO T222 protocol.

\section{BASE COURSE STABILIZATION}

Base course stabilization is the process of constructing a mechanically stabilized layer (MSL) with the use of geogrid (see Figure 1). The term "stabilization" is different from "reinforcement" because the former one is referring to "stiffness enhancement" as well as "stiffness retention for a longer period." In contrast, the term "reinforcement" implies "adding force" (Giroud and Han 2016). This mechanism is only effective if the forces are large which in turn implies that large vertical permanent deformations exist in the aggregate overlying the geogrid.

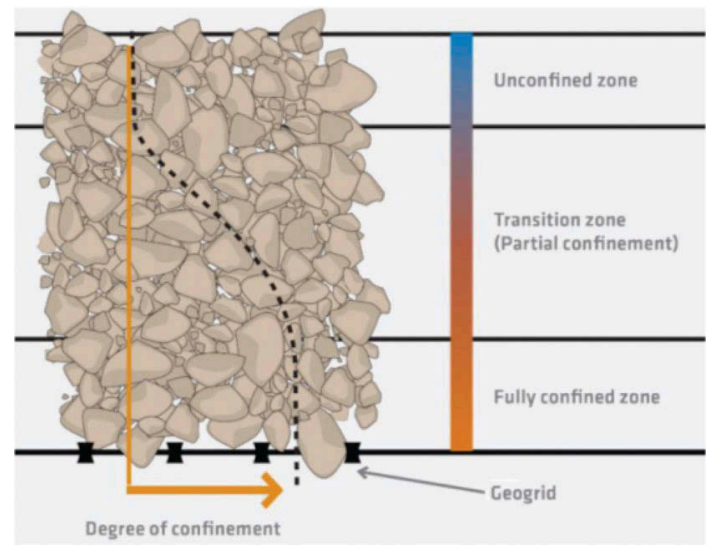

Figure 1. Confinement Zones in an MSL. 
When a geogrid is incorporated into a granular material, the aggregate particles interlock with the geogrid and are confined within the geogrid apertures. As a result, the particles are restrained from moving laterally. The lateral restraint provided by the geogrid contributes to reducing induced strain due to traffic loading and thereby increases the stiffness of the granular layer (Sun et al. 2018; Wayne et al. 2013, 2019; Rakowski and Kawalec 2020). In addition to the lateral restraint, granular particles immediately adjacent to the interlocked particles are themselves restrained by the particle to particle interlock. Thus, the influence of the geogrid inclusion extends beyond the geogrid particle interface. Cook and Horvat (2014) demonstrated the existence of such variation in particle interlocking using a multi-level shear box. The authors found that the influence of the geogrid on the stiffness of a granular layer will decrease in relation to the distance from the geogrid. This can be represented as zones of confinement from fully confined to unconfined as illustrated in Figure 1. Behaviors of confinement due to different geogrid and material types were also investigated through the use of numerical modeling (Jas et al. 2015; Konietzky et al. 2004; Lees 2017; McDowell et al. 2006; Stahl et al. 2014), bender element shear wave measurement technology (Kang et al. 2020; Kim et al. 2020) and measurement of aggregate particle motion using SmartRocks (Liu et al. 2017).

\section{AASHTO T222 TESTING}

Static plate load tests were conducted in accordance with AASHTO T222 (2012) to determine the modulus of subgrade reaction (k-value) using a $762 \mathrm{~mm}$ diameter loading plate setup shown in Figure 2b. The plate stress was applied up to $103.4 \mathrm{kPa}$ at $17.2 \mathrm{kPa}$ increments. Plate deformations were measured and the uncorrected k-value was determined using Equation 1.

$$
k_{u}^{\prime}=\frac{69 k P a}{\delta_{o}}
$$
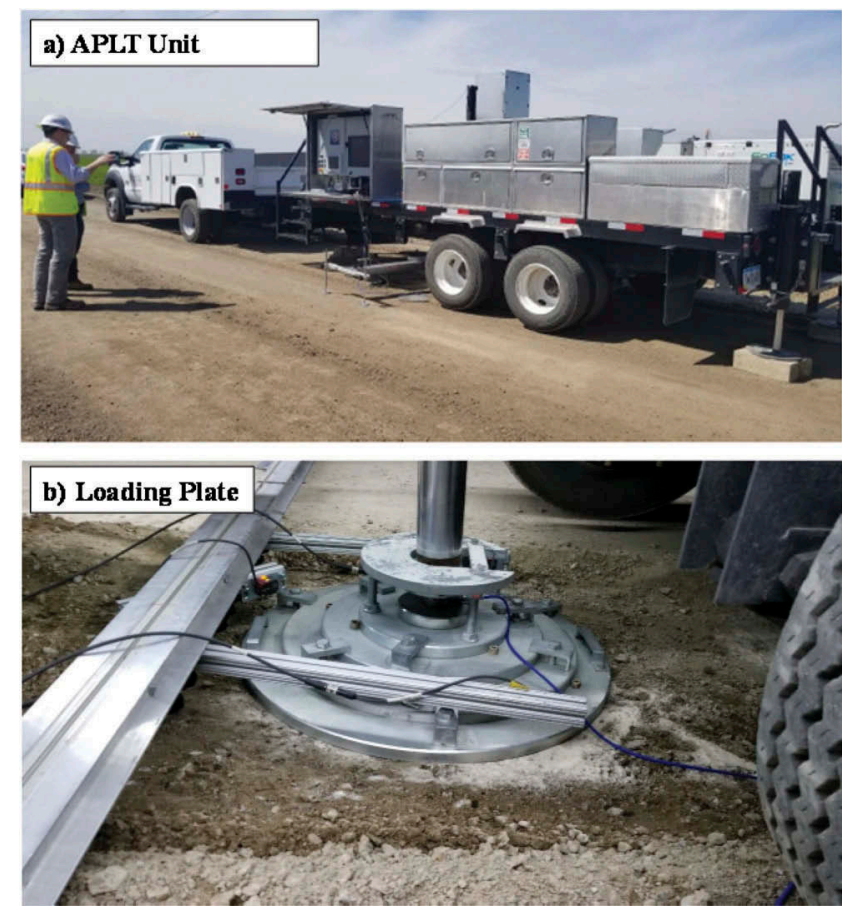

Figure 2. Automated Plate Load Testing (APLT) Setup. 
where, $k_{u}^{\prime}=$ uncorrected modulus of subgrade reaction $(\mathrm{kPa} / \mathrm{mm}), \delta_{o}=$ deformation corresponding to the $69 \mathrm{kPa}$ loading stage $(\mathrm{mm})$. The $k_{u}^{\prime}$ value was then corrected for plate bending to determine the corrected modulus of subgrade reaction $\left(k_{u}\right)$ following the procedure described in the test standard and Equation 2 for $k_{u}^{\prime} \geq 27.14 \mathrm{kPa} / \mathrm{mm}$ and $\leq 271.44 \mathrm{kPa} / \mathrm{mm}$ (note that the unit of $k_{u}$ and $k_{u}^{\prime}$ in Equation 2 is pci). However, the correction for saturation was not performed in this study.

$$
k_{u}=-39.91+5.50 x\left[k_{u}^{\prime}\right]^{0.702}
$$

After the first load sequence, a reload sequence was applied in three loading steps. The reloading curve was used to determine the reload modulus of subgrade reaction $\left(k_{u r}^{\prime}\right)$ at 69 $\mathrm{kPa}$. The $k_{u r}^{\prime}$ value was then corrected for plate bending to determine the corrected reload k-value $\left(k_{u r}\right)$ using Equation 2.

\section{AUTOMATED PLATE LOAD TESTING (APLT)}

The APLT system (see Figure 2) consists of an advanced electronic-hydraulic control system for applying cyclic and static load pulses through circular steel plates and high-resolution sensors for measuring vertical ground displacements (White and Vennapusa 2017). Compared to FWD, the APLT has the advantage of applying a conditioning loading prior to testing and measuring peak, resilient and permanent deformations for each loading cycle. The APLT system had been used for developing permanent deformation models for geogrid stabilized pavement (White and Vennapusa 2017; Tamrakar et al. 2019) and measuring composite and layer-specific moduli for various pavement layers (Vennapusa et al. 2018). In this study, the APLT system with static stresses was used for measuring k-values by following the AASHTO T222 protocol. However, the other studies had utilized the APLT system for measuring the stress-dependent properties of unbound aggregate layers by using repetitive loads with various stress levels (Tamrakar et al. 2019) or loading frequencies (Tamrakar et al. 2021). The load sequences used for measuring k-values are shown in Table 1.

Table 1. Load Sequences for APLT.

\begin{tabular}{lllll}
\hline Load Sequences & Stage & Load Step & Target Applied Load $(\mathrm{kN})$ & Target Applied Stress (kPa) \\
\hline 0 & Seating & 0 & 3.14 & 6.89 \\
1 & Load & 1 & 7.86 & 17.24 \\
& Load & 2 & 15.72 & 34.47 \\
& Load & 3 & 23.58 & 51.71 \\
& Load & 4 & 31.44 & 68.95 \\
& Load & 5 & 39.30 & 86.18 \\
& Load & 6 & 47.16 & 103.42 \\
& Unload & 7 & 31.44 & 68.95 \\
& Unload & 8 & 15.72 & 34.47 \\
& Unload & 9 & 7.86 & 17.24 \\
& Load & 10 & 15.72 & 34.47 \\
& Load & 11 & 31.44 & 68.95 \\
& Load & 12 & 47.16 & 103.42 \\
& Unload & 13 & 7.86 & 17.24 \\
& Unload & 14 & 0.00 & 0.00 \\
\hline
\end{tabular}




\section{PROJECT DETAILS}

The project sites were located in Los Angeles and Santa Clarita, CA. The first project site (Site 1) was located at an intermodal facility and the second site (Site 2) was located on a pavement section of Interstate 5. For Site 1, the geogrid stabilized section consisted of 125mm-thick aggregate base course (ABC) and the unstabilized section consisted of $287-\mathrm{mm}$ thick ABC (see Figure 3). For Site 2, the stabilized pavement section consisted of 118-mmthick $\mathrm{ABC}$ and the unstabilized section consisted of 212-mm-thick $\mathrm{ABC}$. The $\mathrm{ABC}$ for both sites was a crushed miscellaneous base consisting of concrete, asphalt and aggregate. For Site 1, the material consisted of a maximum particle size of $37 \mathrm{~mm}$ with about $5 \%$ fines (particle passing sieve size 200). For Site 2, the material consisted of a maximum particle size of $25 \mathrm{~mm}$ with about $10 \%$ fines. Other properties of $\mathrm{ABC}$ are reported in Table 2 . The stabilized sections were prepared by placing a layer of geogrid at the $\mathrm{ABC} /$ subgrade interface. The properties of multi-axial geogrids are reported in Table 3 . Both sites consisted of considerably firm foundations. The subgrade CBR values, estimated from Dynamic Cone Penetrometer (DCP) test, were higher than 100 for Site 1 and 30 for Site 2 (see Table 2).

\section{a) Site 1}

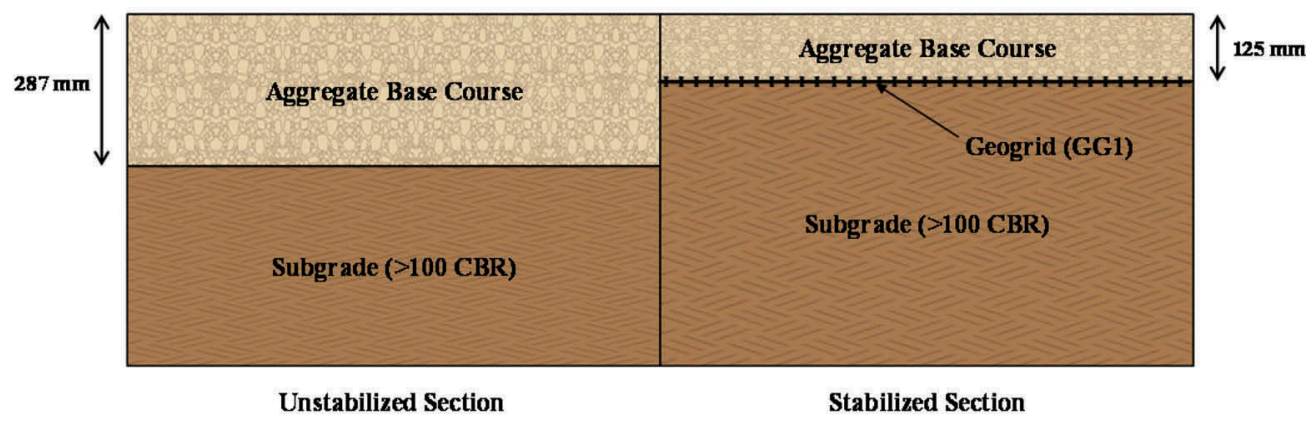

b) Site 2

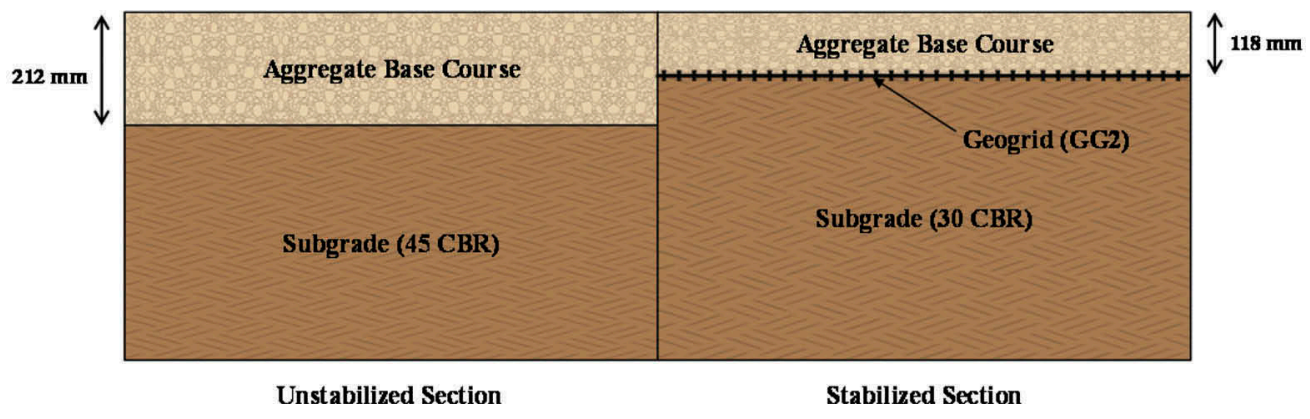

Figure 3. Stabilized and Unstabilized Sections for Sites 1 and 2.

\section{PRESENTATION OF RESULTS}

Figure 4 shows average plate deformation versus applied stress for the two loading cycles using the loading sequences described in Table 1 for Sites 1 and 2. The first load sequence consisted of applying load up to $103 \mathrm{kPa}$, and unloading the plate to achieve $17 \mathrm{kPa}$ contact stress. And, the second load sequence consisted of reloading up to $103 \mathrm{kPa}$, and complete 
Table 2. Section Details.

\begin{tabular}{|c|c|c|c|c|}
\hline \multicolumn{3}{|l|}{ Project Site } & Site 1 & Site 2 \\
\hline \multirow{3}{*}{\multicolumn{2}{|c|}{$\begin{array}{l}\text { Location } \\
\text { ABC thickness (mm) }\end{array}$}} & & Los Angeles & Santa Clarita \\
\hline & & Unstabilized & 287 & 212 \\
\hline & & Stabilized & 125 & 118 \\
\hline \multirow[t]{10}{*}{ ABC Properties } & Material Type & & \multicolumn{2}{|c|}{$\begin{array}{l}\text { Crushed Miscellaneous Base consist- } \\
\text { ing of concrete, asphalt and aggregate }\end{array}$} \\
\hline & \multirow[t]{5}{*}{ Particle size distribution (mm) } & D10 & 0.27 & 0.07 \\
\hline & & D30 & 2.45 & 0.57 \\
\hline & & D50 & 7.33 & 2.20 \\
\hline & & D60 & 10.16 & 4.17 \\
\hline & & D85 & 21.65 & 11.28 \\
\hline & Maximum size (mm) & & 37 & 25 \\
\hline & \multirow[t]{2}{*}{ Soil classification } & AASHTO & A-1-a & A-1-a \\
\hline & & USCS & GW & SW \\
\hline & Fines content & & $5 \%$ & $10 \%$ \\
\hline \multirow{2}{*}{\multicolumn{2}{|c|}{ Existing subgrade CBR (\%) }} & Unstabilized & $>100$ & 45 \\
\hline & & Stabilized & $>100$ & 30 \\
\hline
\end{tabular}

Table 3. Summary of Geogrid Properties.

\begin{tabular}{lll}
\hline Parameters & GG1 & GG2 \\
\hline Product & TX8 & TX130s \\
Rib shape & Rectangular & Rectangular \\
Aperture shape & Triangular & Triangular \\
Rib pitch $(\mathrm{mm})$ & 33 & 33 \\
Mid-rib depth $(\mathrm{mm})$ & $1.6^{\mathrm{d}}, 1.2^{\mathrm{t}}$ & - \\
Mid-rib width $(\mathrm{mm})$ & $0.4^{\mathrm{d}}, 0.7^{\mathrm{t}}$ & - \\
\hline
\end{tabular}

${ }^{\mathrm{d}}$ Diagonal direction; ${ }^{t}$ Transverse Direction

unloading (i.e., achieving $0 \mathrm{kPa}$ contact stress). Results indicated that the rate of increase in deformation is lower for the stabilized section than that for the unstabilized section (see Figure 4), even though the unstabilized section had a thicker ABC than the stabilized section. Further, at the end of the unloading cycle, the unstabilized section showed more deformation than that of the stabilized section. The unstabilized section exhibited 1.76 and 1.51 times more deformation than the stabilized section for Site 1 and Site 2, respectively.

For the second loading cycle, the rate of increase in the deformation of both stabilized and unstabilized sections was similar which are illustrated in Figure 5 and Figure 6. However, there is a difference in deformation between the first and second loading cycles at various applied stresses. The difference in deformation is higher at lower stress. Further, such deformation difference is higher for the unstabilized section than the stabilized section for both sites. Table 4 provides a summary of deformation occurring at various applied stresses.

Table 5 summarizes the results (k values) from the first and second loading cycles. For site $1, k_{u}$ for stabilized and unstabilized sections were $107 \mathrm{kPa} / \mathrm{mm}$ and $75 \mathrm{kPa} / \mathrm{mm}$. Similarly, $k_{u}$ for stabilized and unstabilized sections were $54 \mathrm{kPa} / \mathrm{mm}$ and $42 \mathrm{kPa} / \mathrm{mm}$ for site 2 . Despite the difference in the $\mathrm{ABC}$ thickness, the stabilized section showed a higher $k_{u}$ (a.k.a. modulus of subgrade reaction or $\mathrm{k}$-value) than that for the unstabilized section. Table 6 provides a summary of the modulus of subgrade reaction values, including k-value ratios, for Site 1 and Site 2. The results indicate that the stabilized section having 56\% thinner ABC than that of the unstabilized section demonstrates $43 \%$ increase in k-value for site 1 . Similarly, for Site 2 , the stabilized section shows $28 \%$ higher k-value despite $44 \%$ less ABC thickness. 
a) Site 1

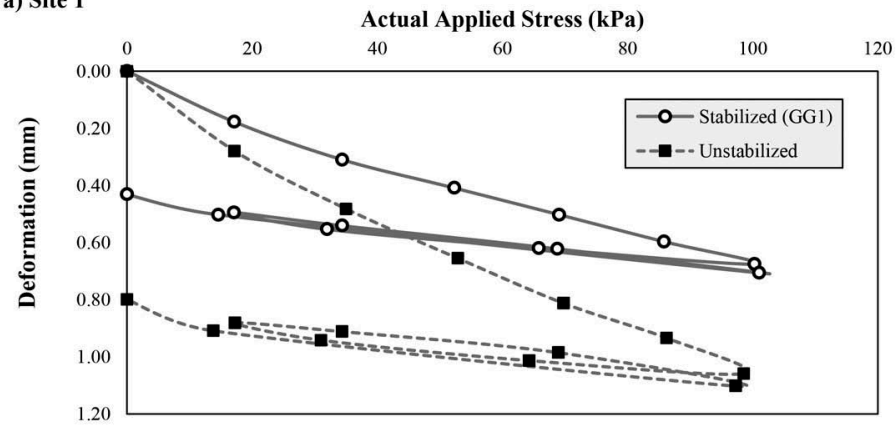

b) Site 2

Actual Applied Stress (kPa)

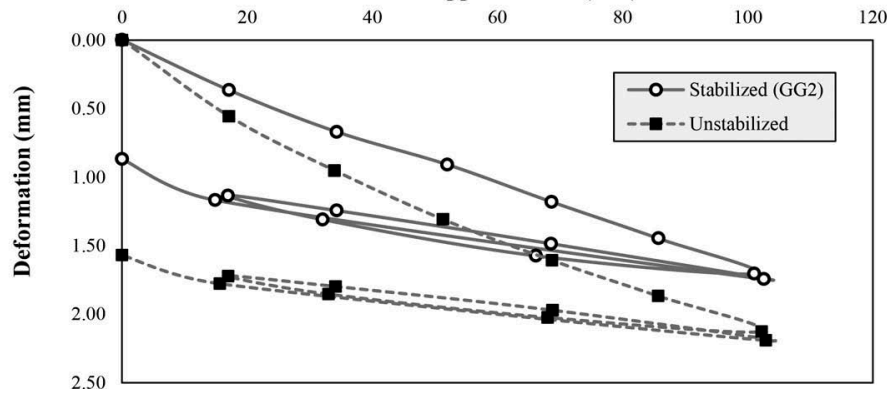

Figure 4. Deformation Under the Plate at Various Loading and Unloading Cycles.

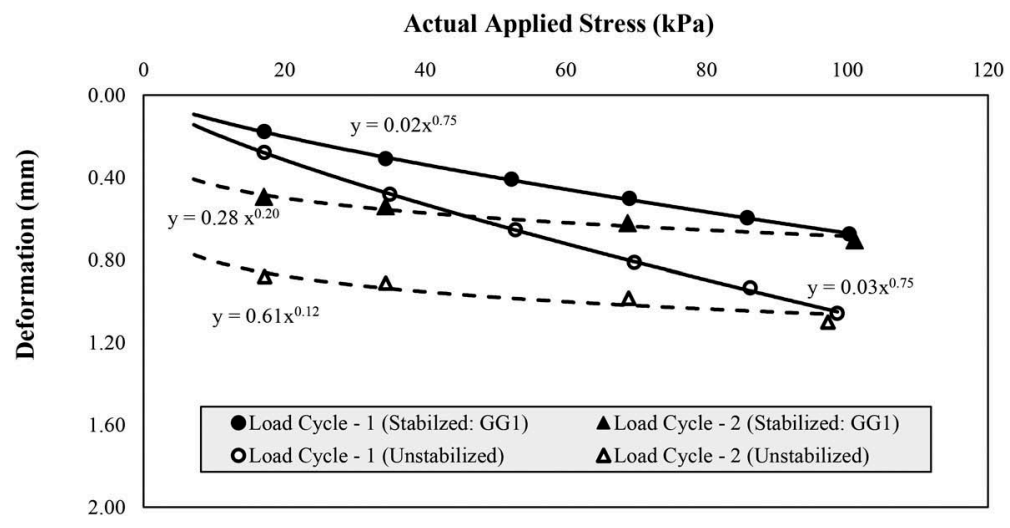

Figure 5. First and Second Loading Cycle for Site 1.

The reload modulus of subgrade reaction $\left(k_{u r}\right)$ values, and the ratio $k_{u r} / k_{u}$ are provided in Table 5. The ratio provides the level of "compactability" of the material and degree of achievable stiffness of the pavement foundation layers. The lower ratio means a better compaction level was achieved and a lower potential improvement in stiffness with additional compaction effort. Hence, this indicates the material is stiffer and more elastic for a better construction platform. Some European specifications (e.g., ATB VAG 2005) recommend the ratio of $300 \mathrm{~mm}$ diameter two-cycle quasi static plate load tests to be $\leq 2.8$ for concrete pavement foundation layers in the top $250 \mathrm{~mm}$ below the pavement and $\leq 3.5$ for the underlying 250 to $500 \mathrm{~mm}$. The higher $k_{u r} / k_{r}$ ratios for unstabilized sections presented in Table 5 suggest that the 


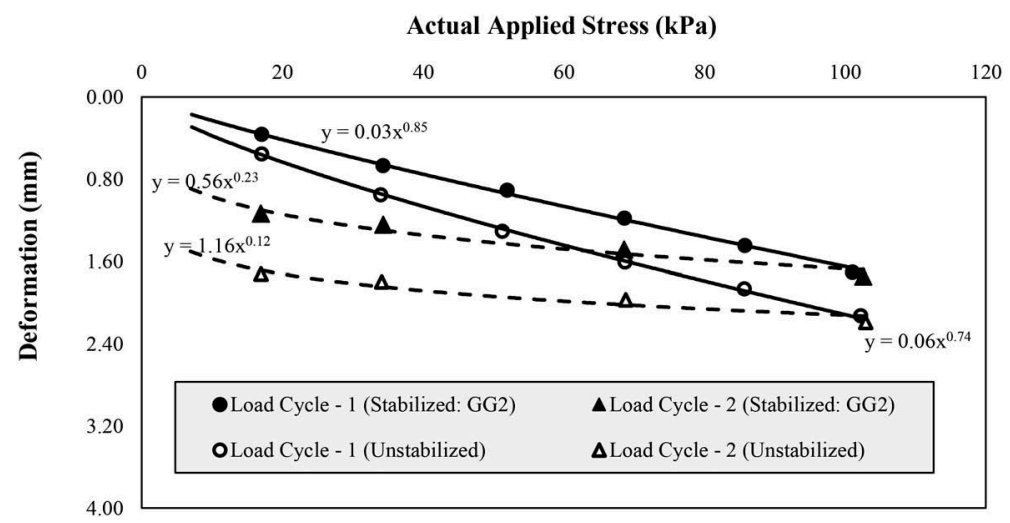

Figure 6. First and Second Loading Cycle for Site 2.

Table 4. Deformation at Various Applied Stresses.

\begin{tabular}{|c|c|c|c|c|c|c|c|c|}
\hline & \multirow{2}{*}{$\begin{array}{l}\text { Applied } \\
\text { Stress } \\
\mathrm{kPa}\end{array}$} & \multicolumn{3}{|c|}{ Deformation $(\mathrm{mm})$ for Stabilized } & \multicolumn{3}{|c|}{$\begin{array}{l}\text { Deformation }(\mathrm{mm}) \text { for } \\
\text { Unstabilized }\end{array}$} & \multirow{2}{*}{$\begin{array}{l}\text { Ratio }= \\
\Delta_{\text {un }} / \Delta_{\text {st }}\end{array}$} \\
\hline & & LC 1 & LC 2 & $\Delta_{\mathrm{st}}$ & LC 1 & LC 2 & $\Delta_{\text {un }}$ & \\
\hline \multirow[t]{3}{*}{ Site 1} & 20 & 0.20 & 0.50 & 0.30 & 0.32 & 0.88 & 0.56 & 1.85 \\
\hline & 40 & 0.33 & 0.57 & 0.24 & 0.54 & 0.95 & 0.42 & 1.72 \\
\hline & 60 & 0.45 & 0.62 & 0.17 & 0.73 & 1.00 & 0.27 & 1.58 \\
\hline \multirow[t]{3}{*}{ Site 2} & 20 & 0.42 & 1.14 & 0.73 & 0.63 & 1.68 & 1.05 & 1.44 \\
\hline & 40 & 0.75 & 1.34 & 0.59 & 1.06 & 1.83 & 0.76 & 1.29 \\
\hline & 60 & 1.06 & 1.48 & 0.41 & 1.44 & 1.92 & 0.48 & 1.16 \\
\hline
\end{tabular}

Note: $L C=$ Loading Cycle; $\triangle=$ Difference in deformation of $L C 1$ and $L C 2$

Table 5. Summary of Results from the First and Second Loading Cycles.

\begin{tabular}{|c|c|c|c|c|c|}
\hline \multirow[b]{2}{*}{ Loading } & \multirow[b]{2}{*}{ Parameters } & \multicolumn{2}{|l|}{ Site 1} & \multicolumn{2}{|l|}{ Site 2} \\
\hline & & Stabilized & Unstabilized & Stabilized & Unstabilized \\
\hline \multirow[t]{2}{*}{ First Loading Cycle } & Deformation $(\mathrm{mm})$ & 0.50 & 0.80 & 1.18 & 1.60 \\
\hline & $\mathrm{k}_{\mathrm{u}}(\mathrm{kPa} / \mathrm{mm})$ & 107 & 75 & 54 & 42 \\
\hline \multirow[t]{3}{*}{ Second Loading Cycle } & Deformation (mm) & 0.17 & 0.11 & 0.45 & 0.31 \\
\hline & $\mathrm{k}_{\mathrm{ur}}(\mathrm{kPa} / \mathrm{mm})$ & 245 & 325 & 116 & 155 \\
\hline & $\mathrm{k}_{\mathrm{ur}} / \mathrm{k}_{\mathrm{u}}$ & 2.29 & 4.35 & 2.13 & 3.73 \\
\hline
\end{tabular}

Table 6. Modulus of Subgrade Reaction (k-value).

\begin{tabular}{lllllll}
\hline & Stabilized & & & Unstabilized & \\
& ABC Thickness $(\mathrm{mm})$ & $\begin{array}{l}\text { k-value } \\
(\mathrm{kPa} / \mathrm{mm})\end{array}$ & & ABC Thickness $(\mathrm{mm})$ & $\begin{array}{l}\text { k-value } \\
(\mathrm{kPa} / \mathrm{mm})\end{array}$ & Ratio* \\
\hline Site 1 & 125 & 107 & 287 & 75 & 1.43 \\
Site 2 & 118 & 54 & 212 & 42 & 1.28 \\
\hline
\end{tabular}

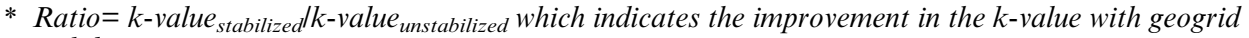
stabilization 
stiffness of the tested pavement foundation layer could have been improved with additional compaction effort prior to testing.

\section{SUMMARY AND CONCLUSION}

Field studies, using an Automated Plate Load Testing (APLT) system, were performed over geogrid stabilized and unstabilized sections at two sites. For Site 1, the aggregate base course (ABC) thicknesses of the stabilized and unstabilized sections were $125 \mathrm{~mm}$ and $287 \mathrm{~mm}$, respectively. Similarly, the ABC thicknesses of the stabilized and unstabilized sections were $118 \mathrm{~mm}$ and $212 \mathrm{~mm}$ for Site 2. The stabilized section consisted of a layer of multi-axial geogrid placed at the interface of $\mathrm{ABC} /$ subgrade. Static loads consisting of loading and unloading cycles were applied in accordance with the AASHTO T222 protocol for determining the modulus of subgrade reaction ( $\mathrm{k}$-value) of stabilized and unstabilized sections.

The key findings of this study are:

- The deformation under the plate increased with the increase in the applied stress. For the first loading cycle, the rate of increase in deformation was higher for the unstabilized section.

- At the end of the first unloading cycles, the unstabilized sections exhibited 1.76 and 1.51 times more deformation than the stabilized sections for Site 1 and Site 2.

- The change in deformation between the first and second cycles with increasing stress was more for the unstabilized section than that for the stabilized section. Therefore, the stabilized section is well compacted and has more uniform stiffness distribution. For this reason, aggregate bases underlain by a multi-axial geogrid could be considered very erosion resistant for the design of rigid pavements.

- The geogrid stabilized sections exhibited a higher k-value than the unstabilized sections despite the reduction in $\mathrm{ABC}$ thickness.

\section{REFERENCES}

AASHTO T222. (2012). Standard method of test for nonrepetitive static plate load test of soils and flexible pavement components for use in evaluation and design of airport and highway pavements. American Association of State Highway and Transportation Officials, Washington DC.

ATB VAG. (2005). Technical Specifications for Roads. Swedish Road Administration, Borlãnge, Sweden.

Cook, J., and Horvat, F. (2014). "Assessment of particle confinement within a mechanically stabilised layer." 10th International Conference on Geosynthetics. Berlin.

Darter, M. I., Hall, K. T., and Kuo, C.-M. (1995). Support under Portland cement concrete pavements.

Farouk, H., and Farouk, M. (2014). "Calculation of subgrade reaction modulus considering the footing-soil system rigidity." Vulnerability, Uncertainty, and Risk: Quantification, Mitigation, and Management, 2498-2507.

Giroud, J. P., and Han, J. (2016). "Mechanisms governing the performance of unpaved roads incorporating geosynthetics." Geosynthetics, 34(1).

Jas, H., Stahl, M., te Kamp, L., Konietzky, H., and Oliver, T. (2015). "Discrete element simulation: Modelling and analysis of a geogrid stabilized sub-base while loaded with a moving wheel." XVI European Conference on Soil Mechanics and Geotechnical Engineering.

Kang, M., Kim, J. H., Qamhia, I. I. A., Tutumluer, E., and Wayne, M. H. (2020). "Geogrid Stabilization of Unbound Aggregates Evaluated Through Bender Element Shear Wave Measurement in Repeated Load Triaxial Testing." Transportation Research Record, SAGE Publications Sage CA: Los Angeles, CA, 2674(3), 113-125.

Kim, J. H., Kang, M., Byun, Y.-H., Qamhia, I. I. A., Tutumluer, E., and Wayne, M. H. (2020). "Bender Element Shear Wave Measurement Based Local Stiffness Characteristics Related to Permanent Deformation Behavior of Geogrid-Stabilized Aggregate Specimens." Geo-Congress 2020: Geotechnical Earthquake Engineering and Special Topics, 517-526. 
Konietzky, H., te Kamp, L., Groeger, T., and Jenner, C. (2004). "Use of DEM to model the interlocking effect of geogrids under static and cyclic loading." Numerical modeling in micromechanics via particle methods, AA Balkema, Rotterdam, 3-12.

Lees, A. (2017). "Simulation of geogrid stabilization by finite element analysis." Proceedings of 19th International Conference on Soil Mechanics and Geotechnical Engineering, Seoul, 1377-1380.

Liu, S., Huang, H., Qiu, T., and Kwon, J. (2017). "Comparative evaluation of particle movement in a ballast track structure stabilized with biaxial and multiaxial geogrids." Transportation Research Record, SAGE Publications Sage CA: Los Angeles, CA, 2607(1), 15-23.

McDowell, G. R., Harireche, O., Konietzky, H., Brown, S. F., and Thom, N. H. (2006). "Discrete element modelling of geogrid-reinforced aggregates." Proceedings of the Institution of Civil EngineersGeotechnical Engineering, Thomas Telford Ltd, 159(1), 35-48.

Rakowski, Z., and Kawalec, J. (2020). "The Technology of Mechanically Stabilized Layers for Road Structures in Cold Regions." Transportation Soil Engineering in Cold Regions, Volume 2, Springer, 63-70.

Saha, S., Gu, F., Luo, X., and Lytton, R. L. (2019). "Development of a modulus of subgrade reaction model to improve slab-base interface bond sensitivity." International Journal of Pavement Engineering, Taylor \& Francis, 1-12.

Shi, X. P., Tan, S. A., and Fwa, T. F. (1994). "Rectangular thick plate with free edges on Pasternak foundation." Journal of engineering mechanics, American Society of Civil Engineers, 120(5), 971-988.

Stahl, M., Konietzky, H., Te Kamp, L., and Jas, H. (2014). "Discrete element simulation of geogrid-stabilised soil.” Acta Geotechnica, Springer, 9(6), 1073-1084.

Sun, X., Han, J., Parsons, R. L., and Thakur, J. (2018). "Equivalent California Bearing Ratios of Multiaxial Geogrid-Stabilized Aggregates over Weak Subgrade." Journal of Materials in Civil Engineering, American Society of Civil Engineers, 30(11), 4018284.

Tamrakar, P., Wayne, M. H., and White, D. J. (2019). "Permanent and Resilient Deformation Behavior of Geogrid-Stabilized and Unstabilized Pavement Bases." Geo-Structural Aspects of Pavements, Railways and Airfield.

Tamrakar, P., Wayne, M. H., White, D. J., and Vennapusa, P. K. R. (2021). "In Situ Assessment of Geogrid Stabilized Flexible Pavement Using Automated Plate Load Testing." Geosynthetics Conference.

Vennapusa, P. K. R., White, D. J., Wayne, M. H., Kwon, J., Galindo, A., and Garcia, L. (2018). "In situ performance verification of geogrid-stabilized aggregate layer: Route-39 El Carbón-Bonito Oriental, Honduras case study." International Journal of Pavement Engineering, Taylor \& Francis, 1-12.

Wayne, M., Fraser, I., Reall, B., and Kwon, J. (2013). "Performance verification of a geogrid mechanically stabilized layer." The 18th International Conference on Soil Mechanics and Geotechnical Engineering, Paris, 1381-1384.

Wayne, M. H., Fountain, G., Kwon, J., and Tamrakar, P. (2019). "Impact of Geogrids on Concrete Highway Pavement Performance." Geosynthetics Conference.

Westergaard, H. M. (1926). "Stresses in concrete pavements computed by theoretical analysis." Proceedings of Highway Research Board, 90-112.

White, D. J., Rupnow, T. D., and Ceylan, H. (2004). "Influence of subgrade/subbase non-uniformity on PCC pavement performance." Geotechnical engineering for transportation projects, 1058-1065.

White, D. J., and Vennapusa, P. K. R. (2017). "In situ resilient modulus for geogrid-stabilized aggregate layer: A case study using automated plate load testing." Transportation Geotechnics, Transportation Geotechnics, 11, 120-132.

Winkler, E. (1867). Die Lehre von der Elasticitaet und Festigkeit: mit besonderer Rücksicht auf ihre Anwendung in der Technik für polytechnische Schulen, Bauakademien, Ingenieue, Maschinenbauer, Architecten, etc. Dominicus. 